\title{
Violências escolares: implicações para a gestão e o currículo *
}

\author{
Afonso Galvão"* \\ Candido Alberto Gomes"*** \\ Clélia Capanema" \\ Geraldo Caliman" \\ Jacira Câmara"*m*
}

\section{Resumo}

Este trabalho apresenta os resultados de uma série de pesquisas exploratórias com o objetivo de investigar as violências escolares entre alunos e professores e algumas das suas implicações práticas. Utilizando métodos quantitativos e qualitativos, focalizaram casos específicos de estabelecimentos públicos e particulares urbanos. Suas conclusões indicam que a escola se caracteriza ao mesmo tempo como autora, vítima e laboratório para a aprendizagem de violências. A existência de discrepâncias significativas entre os conceitos de violências recomendam o seu debate entre docentes e discentes para pactuar normas e condutas comuns. Para isso, é necessária a gestão escolar democrática, não burocrática, com uma liderança efetiva, além de dinâmicas curriculares significativas para os alunos, que enfatizem valores e emoções, no quadro de mudanças paradigmáticas da educação.

Palavras-chave: Violência escolar. Sociologia da educação. Gestão escolar. Currículo.

\section{School violence: implications for management and curriculum dynamics \\ Abstract}

This paper presents the results of a set of exploratory research projects, aiming to investigate the school violence among students and teachers and some of their

\footnotetext{
Conjunto de pesquisas realizadas, no âmbito da Cátedra UNESCO de Juventude, Educação e Sociedade e do Observatório de Violências nas Escolas - Brasil da Universidade Católica de Brasília, realizadas pelo Programa de Mestrado e Doutorado em Educação da mesma Universidade.

*. Doutor em Psicologia,Universidade de Reading, Inglaterra; Professor adjunto e diretor do Programa de Mestrado e Doutorado em Educação da Universidade Católica de Brasília (UCB). E-mail: agalvao@ucb.br

... Doutor em Educação, University of California, Los Angeles; Coordenador da Cátedra UNESCO sobre Juventude, Educação e Sociedade da UCB. E-mail: clgomes@terra.com.br

… Doutora em Educação, University of Southern California, Los Angeles; Professora titular fundadora da UCB. E-mail: cleliac@uol.com.br

… Doutor em Educação pela Università Pontificia Salesiana, Roma; Vice-Coordenador da Cátedra UNESCO sobre Juventude, Educação e Sociedade da UCB. E-mail: caliman@ucb.br

..... Doutora em Educação, Peabody College da Vanderbilt University, EUA; Professora titular fundadora e ex diretora do mesmo Programa da UCB. E-mail: jacira@ucb.br
} 
practical implications. Based on quantitative and qualitative methods, they focused on cases of public and private urban schools. Conclusions suggest that school is at the same time author, victim and a laboratory where students learn to do violence. Significant differences in violence perspectives recommend their discussion between students and teachers to establish a pact on common rules and approved behaviors. Essential conditions for that are democratic, non-bureaucratic, school management, with effective leadership, and curricular dynamics significant for students, emphasizing values and emotions in the framework of paradigmatic change in education.

Keywords: School violence. Sociology of education. School management. Curriculum.

\section{Violencia Escolar: Implicaciones para la Gestión Y la Dinámica Curricular Resumen}

Este trabajo presenta los resultados de un conjunto de proyectos de investigación educativa exploratoria cuyo objeto es conocer mejor las violencias escolares entre estudiantes y profesores y algunas de sus implicaciones prácticas. En estos proyectos se utilizaron métodos cuantitativos y cualitativos, con foco en casos de escuelas urbanas públicas y privadas. Según sus conclusiones, la escuela es al mismo tiempo agente, víctima y laboratorio del aprendizaje sobre la violencia. Las significativas diferencias entre los conceptos de violencias sucedidos entre docentes y estudiantes recomiendan su discusión por parte de los dos grupos, para pactar normas y conductas aprobadas. Para que esto se lleve a cabo es necesario contar con la gestión escolar democrática, no burocrática, con liderazgo efectivo, así como también con dinámicas curriculares valiosas para los estudiantes, con énfasis en valores y emociones, en el contexto de cambios paradigmáticos de la educación. Palabras clave: Violencia escolar. Sociología de la Educación. Gestión escolar. Currículo

As violências nas escolas parecem aumentar em frequência e gravidade como um problema transversal do Ocidente. Esses fatos, em parte midiatizados e em parte submetidos à lei do silêncio, nas salas de aula, escolas e redes escolares, em parte têm raizes em diferentes escalas de valores das pessoas e grupos sociais, que se opõem pelos mais variados fatores. Costuma-se relacionar tais violências à rapidez das mudanças histórico-sociais, ao "mal-estar da civilização", à "crise da escola", à "desagregação da família" e a outros fatores. Entretanto, se o objetivo é encontrar soluções, é preciso, pelo menos, levantar pistas quanto a algumas questões básicas, a exemplo dos conceitos e significados das violências para os participantes e deles extrair implicações para a gestão educacional e a dinâmica curricular. Deixando uma agenda de investigações denunciativas, que devassa o circo dos horrores, este trabalho costura diversas pesquisas para extrair implicações práticas. 


\section{Teorias em busca da realidade em mudança}

A torrente de mudanças sociais e a difusão pelo mundo de novos valores e padrões de comportamento levam as teorias a buscar renovadas explicações. A abertura da escola e a sua democratização teceram uma trama ainda mais complexa. Já nos anos 60 Coleman (1963) verificava que a sociedade industrial mudara os padrões de convivência entre adultos e adolescentes, de modo que estes últimos, passando muito mais tempo entre si, constituiam a sua sociedade, com escalas próprias de valorização social e normas não raro antípodas às da escola. Assim, por exemplo, alunos bem ajustados às exigências escolares, inclusive de aproveitamento, passaram a ser desvalorizados, criando-se estereótipos como o de nerd.

A "antiga" escola, integradora e edificadora da personalidade, passou a ser percebida por educadores e outros adultos como um paraíso perdido, muito melhor que a de hoje, que tem um alunado tão heterogêneo. Tendo a sociologia clássica apresentado sinais de esgotamento, buscam-se novas alternativas de compreensão, como a sociologia da experiência (DUBET, 2002, 2009). Segundo ela, a experiência social se caracteriza pela heterogeneidade dos principios culturais e sociais que organizam as condutas. No caso, os jovens adotam simultaneamente vários pontos de vista, com os indivíduos situados no entrecruzamento de múltiplos círculos sociais, sem, entretanto, participar integralmente de nenhum deles. A identidade é, pois, um trabalho tecido a partir de "cidadanias" ou participações sociais em cada círculo. Por isso, o aluno não age só em função da escola, mas também e sobretudo dos seus grupos de pertencimento. Por sua vez, o professor necessita dos recursos da sua personalidade e carisma (se forem suficientes), já que o seu papel e o da instituição, burocraticamente definidos, não mais dão conta das novas situações. A escola se torna claramente uma arena competitivo-conflitual, onde se confrontam as culturas escolar e adolescentes/ juvenis. Os alunos socialmente privilegiados se integram à cultura juvenil com os desafios à escola mantidos dentro de certos limites, ao passo que os alunos das classes populares reagem às experiências de fracasso pela via da afirmação pessoal, com rebeldia aberta contra a escola. Assim, o termo arena, originado da areia que absorvia o sangue no circo romano, não é exagero diante da teia de violências em parte disfarçadas pelos véus das filosofias e boas intenções.

É verdade que, em 1932, muito antes da abertura da "escola para todos", Waller (1970a, 1970b), um sociólogo pouco conhecido, porém logo descoberto por Antônio Cândido (1973), denunciara o despotismo da escola, onde as gerações se defrontavam, levando a sua ordem social a padecer de uma instabilidade estável. Os vulcões aparentavam dormitar por longo tempo, quando as rebeliões estudantis globalizadas irromperam em 1968 como grandes erupções vulcânicas. Filhas da lava incandescente dessa época são as chamadas teorias da reprodução, que tiveram como marco a obra de Bourdieu e Passeron (1970). Esta desvelou a violência praticada pela escola, especialmente contra os alunos socialmente excluídos, por meio dos requisitos implícitos a 
que eles deviam atender. Além disso, os autores evidenciaram processos mais ou menos sutis para manter controle sobre os discentes, incluindo sanções morais e castigos físicos. De outro lado, porém, os alunos hoje aparecem como vilões por se envolverem no chamado núcleo duro da violência física, como homicídio (ou tentativa), estupro (ou tentativa), danos físicos graves, roubo, assalto a mão armada e vandalismo. Ademais, praticam violências simbólicas, como o uso agressivo da linguagem; a imposição de apelidos, inclusive ligados a estereótipos étnicos e de gênero; 0 isolamento de certos alunos e grupos, além das incivilidades e do assédio moral ou bullying (DEBARBIEUX; BLAYA, 2002). Assim, novos olhos para as bases de legitimação da autoridade vêm abalar os fundamentos da violência historicamente praticada pela escola contra os seus alunos (AQUINO, 1998a, 1998b).

Como existem diferenças de perspectivas sobre o que é violência entre os atores escolares, em particular docentes e discentes, tornam-se difíceis a comunicação e a construção de códigos comuns de conduta. Uma vez que os alunos não são entes passivos, a ordem na escola e na sala de aula resulta do estabelecimento de uma definição da situação que especifica as regras para o comportamento e o desempenho. Esta definição é negociada por professores e alunos em conjunto, à medida que interagem no contexto das atividades (BOSSERT, 1979), o que destaca a importância da visão e conceituação de violências pelos dois grupos.

Em abono dessas afirmações, a pesquisa sustenta que o clima da escola, reunindo aspectos racionais e emocionais, intrínsecos ao processo educativo, está relacionado ao aproveitamento. Por isso, fica claro que a gestão escolar e a dinâmica do curriculo precisam assegurar uma educação significativa para o alunado.

\section{Violências escolares no Brasil}

As violências escolares têm presença recente na mídia e na pesquisa social, entretanto, no ocaso do Império, um artista, não um cientista, revelou os subterrâneos da escola e da sociedade brasileiras por meio de 0 Ateneu (POMPEIA, 1954). 0 romance (realista-naturalista?) exibe uma escola hipócrita, estratificada em garotos dominantes e dominados, "másculos" e "emasculados", por meio de um currículo oculto muito mais importante que o formal. Desse estabelecimento, microcosmo da sociedade da época, saiam os seus "quadros dirigentes" para manter a ordem social "como dantes no quartel de Abrantes".

Com esse relativo silêncio, as violências "contemporâneas" começaram a ser observadas nos anos 1980, quando o governo militar instituiu a "abertura política", que desembocaria no período transicional da "Nova República". Mesmo gradativo, o destampar da panela de pressão patenteava os problemas das periferias urbanas, das forças de segurança e da expansão das redes do crime organizado. As escolas eram visadas pelo vandalismo, praticado de fora para dentro, e, segundo as poucas pesquisas, reduzido 
pelo policiamento ostensivo. Entretanto, surgia um conjunto de novos atores, apenas em parte ligados ao empobrecimento da chamada "década perdida": os grupos do crime organizado transnacional, que não só passaram a disputar o mercado interno de drogas, como a usar o Brasil como seu entreposto. Nos anos 1990 a pesquisa se multiplicou, inclusive com trabalhos da UNESCO, e abordou a violência juvenil tanto nas periferias urbanas quanto nas camadas médias, neste caso ante os impactos do crime contra o índio Galdino, em Brasilia (WAISELFISZ, 1998; MINAYO et al., 1999; ABRAMOVAY et al., 1999). Partindo do vandalismo, as violências escolares aumentaram a sua visibilidade com agressões contra as pessoas, tanto alunos entre si quanto entre alunos e professores, enquanto se difundiam pelas cidades médias e regiões menos industrializadas. Ao mesmo tempo, o ensino fundamental passava a incluir até $95,4 \%$ da população em idade própria em 1999, estabelecendo a escola pública para quase todos (embora precária em pessoal e infraestrutura), que tentava encaixar inéditas diversidades nos velhos moldes da singularidade. As pesquisas se expandiram à medida que se manifestavam a crise de eficácia socializadora da escola e a banalização das violências (SPOSITO, $2001,2009)$. Apesar de os problemas sociais serem ressaltados no novo período político, não se encontram constatações científicas que relacionem claramente pobreza e violências (ZALUAR; NORONHA; ALBUQUERQUE, 1994; CANO; SANTOS, 2007), mas, sim, entre as atividades do tráfico de drogas e armas e as violências. As disputas de poder entre grupos externos, com seus reflexos na escola, e entre grupos intraescolares, afora as violências por motivos aparentemente pouco relevantes, passaram a envenenar 0 clima de estabelecimentos, de modo que colegas foram apontados como perturbadores por elevado número de alunos (ABRAMOVAY; RUA, 2002). Em outros termos, num tripé de expressivas preposições, à violência da e contra a escola ganhou relevo a violência nas escolas, estas se revelando laboratórios da produção de violência ( MOIGNARD, 2008). Assim, em poucos anos catalisaram-se no Brasil a violência do crime organizado, a heterogeneidade da escola de massas, a deslegitimação da autoridade escolar, o elevado fracasso dos alunos, a falta de significação dos currículos e o desejo de protagonismo dos jovens, que passaram a conviver mais entre si.

Os problemas se tornam mais complexos e graves, ao passo que as respostas das escolas se apresentam proporcionalmente frágeis e dispersas. Afora a gestão escolar democrática, com os obstáculos inerentes à sua expansão e aprofundamento, ampliouse a abertura da escola à comunidade nos fins de semana (SANTOS, 2001; SILVA. 2001; GONÇALVES; SPOSITO, 2002, 2009; DAYRRELL et al., 2009), inclusive por meio do programa Abrindo Espaços, da UNESCO (NOLETO, 2001; GOMES, 2008), adotado pelo Ministério da Educação como política pública (Escola Aberta). As pesquisas dos anos 1990 constataram as relações entre baixa autoestima e vitimização (MARRIEL et al., 2006), bem como, sem unanimidade, o papel mediador entre escola e violência (NJAINE; MINAYO, 2003) dos estratos sociais (menos favorecidos), do sexo (masculino) e da dependência administrativa da escola (pública). Apresentam-se como soluções a mediação de conflitos na escola, bem como políticas públicas abrangentes e articuladas, 
indispensáveis, embora difíceis de tecer e mais ainda de executar dentro dos paradigmas burocráticos existentes (CHRISPINO, 2007; CHRISPINO; DUSI, 2008). Outro caminho tem sido a formação continuada de educadores, que aparentemente manifesta resultados significativos quando não segue moldes ortodoxos (GONÇALVES et al., 2005).

\section{Que são violências para professores e alunos?}

Em que pese a alta relevância das pesquisas de grande porte, as pequenas pesquisas exploratórias continuam a exercer o seu papel de gerar questões e de colocar em dúvida "verdades" estabelecidas. Por isso, a fim de melhor conhecer as áreas de convergência e divergência entre os grupos docentes e discentes, se desenvolveu uma pesquisa exploratória sobre as definições de violências. Selecionaram-se três escolas consideradas bem sucedidas do Distrito Federal: uma pública e duas particulares, das quais uma confessional e outra leiga. Foram aplicados questionários sobre a categorização de atos como violências de maior ou menor gravidade ou não violências a docentes (OLIVEIRA, 2003; OLIVEIRA; GOMES, 2004) e a alunos do ensino médio (FERNANDES, 2006).

Os resultados revelaram que, na opinião dos professores, independente da escola, as violências são "democráticas", não estando ligadas à composição social do alunado. As respostas mostraram ainda que: 1) houve consenso quanto ao elevado grau de gravidade de brigas, insultos, alunos baterem em colegas menores, agressões a professores, intimidação mediante recursos psicológicos, expressões de preconceito racial e prática de atos de conotação erótica com colegas; 2) para a maioria, se os professores tratam os alunos ironicamente, gritam com eles, expulsam-nos de sala de aula e fazem publicamente comparações entre eles, tratava-se de violências pouco graves, o mesmo se aplicando ao uso de detectores de metal e câmeras pela escola; 4) para um grupo pouco menor que $10 \%$, a atitude crítica dos alunos era violência grave, enquanto o professor gritar, insultar alunos e intimidá-los por meios psicológicos não constituía violência. Quanto às diferenças institucionais, os professores da escola confessional se revelaram mais severos, enquanto os da escola leiga foram mais liberais. Os docentes da escola pública, com o alunado mais heterogêneo, foram os mais preocupados com as violências. Os demais apresentavam menos motivos para tanto, visto que ambas as escolas particulares mantinham bedéis para supervisionar os alunos.

No que se refere à pesquisa com os alunos das mesmas escolas, verificou-se a convergência da maioria quanto a: 1) não considerar como violências o uso de câmeras ou detector de metais pela escola e o professor expulsar alunos de sala de aula; 2) classificar como violências muito graves o uso de armas na escola, o furto ou roubo de telefones celulares e os insultos e agressões de alunos a professores; 3 ) conceituar como violências pouco graves escrever nas carteiras e paredes, usar palavrões e apelidos ofensivos, insultar e chantagear outros alunos e praticar atos de conotação erótica com os/as colegas (FERNANDES, 2006). Apesar da convergência de juízos da maioria, minorias expressivas opinaram com maior ou menor rigor. 
Portanto, o que muitos desconsideravam como violência desagradaria ou ofenderia a um número ponderável de discentes. De modo geral, as violências simbólicas, inclusive manifestações de preconceitos, foram mais dificeis de ser percebidas tanto por professores quanto por alunos, sobretudo por estes últimos, o que confirma a literatura. Em face da sua menor tangibilidade, a admissão dessas violências é mais facilmente negociável entre docentes e discentes (BOSSERT, 1979), o que abre caminho para se trivializarem. Nesse desvão medra o silêncio das vítimas, obedecendo à lei dos mais fortes (DEBARBIEUX, 2007).

Cotejando as respostas dos grupos docente e discente, Fernandes (2006) constatou que ambos divergiram sobre o nível de gravidade de situações como brigas entre alunos, o professor comparar alunos publicamente, a prática de atos de conotação erótica com os colegas e os insultos em todos os casos, envolvendo alunos entre si e professores. Os juízos dos docentes tenderam a ser mais rigorosos, embora mais lenientes quanto a si mesmos e mais severos quando as violências dos alunos se dirigiam contra eles, professores.

Comparando as escolas pública e particulares, tanto professores quanto alunos foram mais rigorosos nas últimas que na primeira. 0 maior desencontro ocorreu na escola pública, com ampla heterogeneidade social e maior incidência de fracasso escolar, sugerindo, ao mesmo tempo, amplas possibilidades de conflitos e necessidade de clarificar normas e estabelecer acordos de conduta. Daí se pode inferir que estratégias de mudança devem focalizar o estabelecimento como um todo, em vez de cada professor individualmente. Nesse sentido, deslocar o educador da escola para "capacitações" pode ser muito menos efetivo que atuar com eles em torno do projeto escolar e das suas dificuldades especificas.

As divergências de conceituação de violências entre professores e alunos foram reveladas também por um estudo de caso, focalizando uma escola pública em área socialmente desprivilegiada (SILVA, 2004). Como em outros locais, o trabalho captou a percepção dos docentes de que a escola é invadida pela violência do seu bairro, onde a população tinha estruturas familiares frágeis e enfrentava dificuldades econômicas e sociais. Os participantes assinalaram reiteradamente que as normas são pouco conhecidas, tanto por alunos quanto por professores. Estes últimos foram categóricos ao afirmar que a familia "não põe limites", nem "oferece educação", no sentido da formação de valores e atitudes. Entretanto, os professores caíram em contradição: se as violências decorriam da "falta de educação em casa", eles concebiam o papel do magistério como o de transmitir conteúdos. Ou seja, apesar de o aluno ser "vazio" de valores, atitudes e comportamentos esperados pela escola, parte ponderável dos professores considerou o seu trabalho como meramente informativo. Se as violências tinham origem nessas lacunas, fechava-se um círculo vicioso: nem a família, nem a escola delas cuidava. 
Ainda, para uma parte dos docentes, os alunos chegavam agressivos a um ambiente cujo currículo era pouco significativo, pelo amplo hiato em relação às culturas adolescentes e juvenis. Para alguns deles, o discente era receptivo quando se falava "com jeito" e só se podia educá-los num trabalho conjunto com a familia. Para outros, o alunado era indiscriminadamente refratário a orientações. Por seu lado, alunos se expressaram em favor de uma escola mais atraente e viva, bem como denunciaram violências simbólicas praticadas pelo corpo docente: "Os professores deveriam falar com mais educação [...]". Então, pode-se concluir que um dos passos para o clima escolar favorável é a expressão negociada e clara de normas, por meio de um pacto entre os atores escolares. Embora se tenham encontrado evidências sobre o processo, mas não sobre os resultados, escolas e redes escolares têm elaborado regimentos e códigos de conduta participativamente (MARQUES, 2006; SCHMITZ, 2007), o que torna os alunos coautores dos compromissos. Nesses casos, é preciso evitar a ingenuidade de fazer sucessivas concessões em face de comportamentos violentos, com a escola recuando cada vez mais os limites (BOSSERT, 1979).

\section{As violências e a práxis educacional}

Diversas pesquisas investigaram as perspectivas que alunos e professores tinham sobre as violências e os seus efeitos na práxis cotidiana. Os adolescentes participantes da pesquisa de Ribeiro (2004) relacionaram violência a noções como agressão, falta de respeito, abuso sexual, violação dos direitos humanos, falta de liberdade de escolha e desvalorização do ser humano. Aqui foi enfatizada a queixa da falta de um lugar de escuta, o que contribui para fortalecer a lei do silêncio. De modo consistente, Galvão (2003) investigou uma escola bem-sucedida e caracterizada pelo desenvolvimento de atividades promotoras da paz, com ênfase não só no diálogo, como na liberdade dialógica, o que possibilitava a atuação sobre intenções que, de outra forma, poderiam representar passagem aos atos violentos.

Também emergiu da pesquisa de Ribeiro (2004) a visão, por parte dos estudantes, da escola como instrumento de exclusão social e, por isso, promotora das violências. Ademais, em outras pesquisas (LOPES, 2004; LOPES; GALVÃO, 2004; PENKAL, 2007), a escola foi retratada como lugar de aprendizagem da violência, em que estudantes já envolvidos com situações de violência organizada intimidavam professores e colegas, servindo inclusive de exemplos sobre o caminho a ser trilhado para o sucesso no desafio à autoridade (do professor) e no questionamento ao próprio sucesso profissional dos professores. Nesse sentido, confirma-se a pesquisa de Moignard (2008) na França e no Brasil, que concluiu ser a escola um laboratório de violência, em vez de uma instituição apenas invadida pela violência do seu meio.

Os estudantes da pesquisa de Ribeiro (2004) assinalaram também a parcela de responsabilidade da escola. Declararam, por exemplo, que os professores tendiam a ser desmotivados, faziam longas e constantes greves, a qualidade do ensino era ruim 
e faltava vínculo afetivo no contexto da aula. Em grande parte, isso foi confirmado por Lopes e Galvão (2004), que estudaram percepções de professores. Revelou-se 0 preconceito que uma parte dos docentes tinha contra o local de moradia dos alunos, onde quase sempre estava o estabelecimento. Ao pesquisar a ansiedade de professores que trabalhavam em escolas violentas, Galvão (2004) mostrou que os professores mais antigos viam a sua atuação profissional como um castigo da autoridade educacional, enquanto os novatos entendiam estar ali como sacrifício necessário para, depois, conseguirem algo melhor. 0 discurso predominante dos professores, em ambos os casos, era de resignação. Pensavam a escola como uma espécie de formalidade que servia apenas para responder às necessidades da lei que a obriga a existir. Foi afirmado reiteradamente que os estudantes não levavam a escola a sério, lá estavam por serem obrigados, eram desmotivados e não se comportavam adequadamente. Diante disso, a resposta dos professores era de apatia, conformismo, individualismo e desmobilização, que, por sua vez, trazia o adoecimento psíquico com ansiedade e depressão.

Por outro lado, também têm sido investigados os fatores que levam à violência juvenil. Sabe-se que jovens infratores geralmente possuem uma rede de amigos que também integra o mundo do crime. Isto sugere que jovens têm dificuldades em resistir à pressão grupal para cometerem atos ilegais, o que reafirma a importância atribuída aos grupos de colegas pela literatura. A pesquisa de Penkal (2007), com efeito, verificou que, embora a pressão do grupo possa influenciar o comportamento delinquente, existem indivíduos capazes de a ela resistir. Deve ser enfatizado que não é somente a coerção grupal que leva à violência adolescente. Esta é uma situação multifacetada, em que se deve compreender o indivíduo na sua situação histórica em relação a outros indivíduos. Associada à relação entre amigos, está o relacionamento do adolescente com os pais, que tem como base, frequentemente, laços afetivos pobres e diálogos limitados, num contexto familiar e emocional precário (PLACCO et al., 2002).

Com efeito, Lima (2010), focalizando o relacionamento entre adolescentes em um estudo de casos múltiplos, de escolas consideradas muito violentas, concluiu que as escolas não se compunham de apenas uma arena onde, conforme Waller (1970b), se entrechocavam educadores e educandos. Estes últimos tendiam a unir-se contra os adultos quando se tratava de negociar normas gerais da escola, no entanto, os próprios discentes se enfrentavam em subarenas, onde os seus grupos disputavam continuamente o prestígio e a força entre si, praticando violência simbólica e física contra os colegas. Como revelado por Coleman (1963), ao conviverem por mais tempo com os seus iguais, os adolescentes se tornaram mais dependentes dos seus próprios valores, códigos de conduta e critérios de estratificação. Tais grupos, nas escolas pesquisadas, se submetiam a líderes que os instrumentalizavam em processo de dominação que expressava uma vontade de potência, na maioria das vezes aparentemente inconsciente. Dai a caracterização deles como "senhores" e "escravos", fundamentada em Nietzsche (2006). Educadores e educandos atuavam reciprocamente como opressores e oprimidos, tal o poder 
acumulado pelos últimos. Afora essas relações, uma parte dos estudantes atuava como opressora dos próprios colegas, em certos casos espelhando a divisão do bairro em gangues. Nesse contexto, como nos guetos de paises ocidentais e, no Distrito Federal, mesmo alunos de escolas particulares (GOMES et al., 2006), não era possivel sobreviver sozinho. Tornava-se indispensável pertencer a um grupo, onde, não raro, se efetuavam ritos de passagem (um dos mais comuns era o novo membro apanhar de todos) e onde costumava haver um código de solidariedade entre eles quando supostamente atacados. Ou seja, o adolescente tinha a "escolha" de ser vitimizado sozinho ou nos confrontos intergrupais, neste caso por lealdade ao seu grupo. Porém, a relação senhores/escravos se manifestava também nas violências intragrupais. Assim, como foi narrado aos pesquisadores, certa vez uma adolescente foi obrigada a despir-se no banheiro e ser filmada com um telefone celular, para chantagem futura ou imediata. Um grupo de garotos imobilizou uma colega para levantar-lhe a roupa e dela abusar. Com isso, as relações escravistas se ocultavam graças ao silêncio humilhado das vítimas, que, muitas vezes, culpavam a si mesmas. Com fundamento em Bosacki (2005), o autor alertou que 0 silêncio reduz a criatividade e suscita sentimentos de desvalorização e auto-ódio. Além do silêncio interpessoal, o intrapessoal, provocado sobretudo pela exclusão do grupo, pode levar ao isolamento e ao desligamento do selfe dos outros. Nesse sentido, a lei do silêncio impera porque falar é um atributo de poder do senhor, não do escravo.

Estas redes de maus tratos, constatadas por Lima (2010) nos porões obscuros da escola, como Pompeia (1954) já havia denunciado n'O Ateneu, requerem melhor compreensão das violências no contexto juvenil e escolar, em particular do entendimento dos adolescentes sobre as relações crime-punição. Retornando à pesquisa de Penkal (2007), as representações sociais de estudantes sobre crime e castigo revelaram a convicção de que, no Brasil, pessoas que cometem crimes recebem sanções muito leves ou nenhuma. Além disso, para os jovens entrevistados, quando há punição, esta não envolve re-educação e reintegração social. Para os participantes, o Estatuto da Criança e do Adolescente é uma licença para matar. Faltava a eles compreensão mais profunda da Lei, sobre a qual sabiam apenas que menores de idade, autores de crimes, ficavam presos por, no máximo, três anos, quando ficavam. Assim, considerando que as pessoas tendem a agir de acordo com suas representações e que adolescentes constituem disposto a testar limites e expor-se ao risco, é urgente desfazer a sua perspectiva equivocada da Lei. Como as violências frequentemente se manifestavam no contexto de adolescentes e crianças de famílias desestruturadas, as entrevistas constataram a ausência da função paterna, capaz de estabelecer limites. Se esta função não é adequadamente exercida em casa, cabe ao Estado exercê-la.

\section{Implicações para a gestão escolar}

Fica claro que a gestão escolar, é ao mesmo tempo, parte do problema e da solução. Nesse sentido, Carreira (2005) traçou o quadro de duas escolas do Distrito Federal, analisando a dinâmica das violências no ambiente escolar, na busca de carac- 
terizar o protagonismo da gestão (aqui entendida como constituída pelos diretores, vice-diretores, orientadores e coordenadores). Um dos estabelecimentos era privado e leigo, localizado em área de renda média alta de Brasília, enquanto o outro, da rede pública, se encontrava na periferia, abrigando alunado de renda média e baixa.

Apesar da negação inicial de violência, por parte de professores e gestores, verificaram-se ameaças, agressões verbais, brigas, intimidação sexual, uso de armas, assédio moral e depredações. Essa negação pode ser indício de que os atores desconheciam o que se caracteriza como violência escolar, conceito eclipsado pela lei do silêncio. Esse desconhecimento levava ao despreparo declarado pelos professores para lidar com o problema, sugerindo a urgência de incorporar essa temática na formação profissional. Carreira concluiu que a alternativa para fazer face às violências é a gestão democrática, que envolve a participação de todos, leva em conta suas necessidades, prioridades e características. Segundo os gestores ouvidos, afora esporádicas medidas de acordo e conciliação, praticavam-se a coerção e a punição. Professores e alunos apontaram como medidas eficazes 0 diálogo, os debates, as palestras, os seminários sobre o tema, a disciplina bem definida na rotina escolar e a comunicação mútua entre alunos e professores e entre a escola e a comunidade. 0 estudo propôs reformular a formação de gestores.

Em convergência, Lira (2010) e Lima (2010), avaliando um projeto de segurança em cinco escolas públicas consideradas violentas, em áreas socialmente desfavorecidas do Distrito Federal, concluíram que existia uma via de mão dupla entre o clima escolar e a prática de violências. Entre ambos se estabelecia uma espiral acumulativa, onde o clima, inspirando mal-estar e desconfiança, contribuía para mais violências, que, por sua vez, tendiam a se agravar (e vice-versa). 0 clima favorável, constatado num só estabelecimento, revelou-se intimamente ligado à gestão democrática, ao compartilhamento de decisões, à descentralização de poder, ao espírito de equipe dos educadores e à liderança carismática da diretora. Enquanto esta circulava, acessivel, pelos diversos ambientes, as demais unidades escolares se caracterizavam pela gestão e liderança burocráticas, autoritárias, centradas não nas pessoas, mas nos processos burocráticos, entre os quais se destacava a aplicação de punições aos alunos, em geral expulsos de turma.

Outro aspecto importante da mesma pesquisa foi explorado por Santana (2009): policiais do Batalhão Escolar da Polícia Militar, que recebiam formação especial, eram destacados até permanentemente para assistirem escolas consideradas de elevado risco. Os agentes, nos casos focalizados, quase sempre se integravam bem ao ambiente escolar, inclusive na prevenção das violências. No entanto, a investigação detectou fronteiras difusas entre as funções de gestores escolares e policiais. Com óbvia inadequação, alguns diretores e professores delegavam aos policiais o trabalho "pesado" de aplicação de sanções e utilizavam a sua presença na escola como elemento de dissuasão para problemas meramente disciplinares. Eis que a presença quase permanente dos agentes na escola levava a uma redefinição parcial imprópria dos papéis profissionais de ambos os grupos. 
Ainda no capítulo da gestão, uma pesquisa exploratória, ouvindo adolescentes em grupos focais, verificou que as violências da/na/contra a escola eram comuns a estabelecimentos públicos e particulares do Distrito Federal (GOMES et al., 2006). A principal diferença constatada, porém, foi o tratamento dispensado às ocorrências, além do grau de prevenção. Ao passo que as unidades públicas com frequência negligenciavam o controle da entrada de pessoas e outras medidas, as particulares, preocupadas com o seu conceito e o mercado, agiam do modo mais rápido e silencioso possível. 0 ingresso e a movimentação de alunos e outras pessoas eram rigorosamente observados, havia pessoal não docente que efetivamente atuava na segurança (em geral "bedéis") e encaminhava para punições os alunos que cometessem faltas observáveis, assim que estas ocorriam. Com isso, o alunado tomava conhecimento de que as infrações eram sistematicamente punidas, o que dissuadia muitos de praticá-las, mas os fatos graves eram administrados de modo a não transpirarem para fora dos limites escolares, utilizando até o recurso da na expulsão.

Aliando estas constatações às de Guimarães (2008), conclui-se que a escola particular também valorizava a lei do silêncio. Em pesquisa com orientadores educacionais de estabelecimentos privados de Brasília, a autora verificou inicialmente a negação das violências e a admissão apenas de atos de "indisciplina". Parte considerável das participantes revelou dificuldade de compreender 0 assédio moral, ou bullying, embora a superação deste fizesse parte do projeto pedagógico de metade das escolas investigadas. Em certos casos, havia abordagem interdisciplinar, com educação de valores e trabalho com as vítimas, autores e testemunhas. Assim, além da preocupação com o prestígio da instituição, pode-se sugerir que a lei do silêncio também fosse aplicada seletivamente a certas formas de violência. Havendo a dificuldade de compreender o assédio moral, este podia tornar-se invisivel para os educadores ou, mesmo, ser considerado um problema a ser resolvido entre alunos.

\section{Vandalismo e currículo}

Como o trabalho educativo carente de significado contribui para o aborrecimento dos jovens na escola (NIZET; HIERNAUX, [19-]) e, frequentemente, para a prática de violências, o problema precisa ser abordado não só do ponto de vista da gestão, mas também do currículo. Uma pesquisa abordou o vandalismo, forma de violência dos alunos contra o patrimônio, estabelecendo três enfoques para a sua delimitação: 1) o vandalismo como resultado da coação dos gestores ou de determinados professores, ao vigiarem ou reprimirem alunos que, de alguma forma, reagiam às normas escolares; 2 ) o vandalismo como efeito do transbordamento das tensões do entorno da escola; 3 ) o vandalismo como decorrência de práticas pedagógicas que priorizavam aula expositiva, conteúdos e cognição, em detrimento da afetividade, formação de valores e aprendizagem da convivência (ALMEIDA, 1999). 
A pesquisa qualitativa se realizou em três escolas de educação básica do Distrito Federal, duas públicas e uma particular. Concluiu-se que os educadores se preocupavam apenas com os efeitos da destruição provocada pelos alunos, sem se importarem com os motivos dessas ações. 0 trabalho salientou que, entre alguns professores e alunos, havia o anseio pela inclusão de atividades e conteúdos curriculares que desenvolvessem valores e atitudes de cooperação e que preparassem melhor para a vida, em vez de um curriculo eminentemente informativo, pouco relevante ou compreensivel para o alunado. Assim, concluiu-se que a proposta curricular precisa ter como objetivo maior transformar a escola num âmbito de realização pessoal, capaz de transformar padrões de comportamento, produzir ideias, conciliar alternativas e administrar (além de ensinar a administrar) conflitos.

\section{Conclusões}

Esta série de pesquisas clarifica porque cabe tratar de violências escolares, no plural. A escola é autora, vítima e palco de violência. É autora quando pratica a exclusão social por meio de processos mais ou menos sutis, semelhantes a armadiIhas, para uma parte dos alunos, produzindo e reproduzindo a exclusão social. É vítima, quando seus gestores e docentes são hostilizados, em parte como reflexo da violência que ela produz. É também vítima, quando o vandalismo se torna válvula de uma panela de pressão muito aquecida. Por fim, é palco de violência quando no seu ambiente se desenrolam conflitos entre os seus membros, e quando se torna também lugar de aprendizagem de violências.

Em lugar da falta de nitidez dos valores sociais e da indefinição quanto a normas e limites, é imprescindivel um ambiente de transparência. Mudou o mundo à volta da escola, da mesma forma que mudaram os seus alunos. A escola edificadora da personalidade e integradora, que preenchia os seus discentes como tabula rasa, não é mais viável. Seus alunos reagem a essa imposição unilateral, exercem protagonismo e desejam ser coautores do processo educativo. Trata-se de uma mudança paradigmática, da pedagogia monológica para a pedagogia dialógica (FREIRE, 1975). Com isso, a gestão se exaure na abordagem punitiva, com eficácia decrescente. É preciso a gestão democrática, que pressupõe a participação, o diálogo e normas claras, explicadas, negociadas quando for o caso, não a anomia ou o império da lei do mais forte ou mais vocal. 0 currículo afunilado na razão e nas informações, conforme os padrões da modernidade, necessita de nova dinâmica que associe cognição e afeto, para ser significativo para a realidade do aluno. Chame-se a isso crise da modernidade ou pós-modernidade, a sociedade já não é a mesma. Assim, a escola não continua a máquina do tempo dentro dela. 


\section{Referências}

ABRAMOVAY, M. et al. Gangues, galeras, chegados e rappers: juventude, violência e cidadania nas cidades da periferia de Brasília. Rio de Janeiro:

Garamond, 1999.

ABRAMOVAY, M.; RUA, M. G. Violências nas escolas. Brasília, DF: UNESCO, 2002.

ALMEIDA, S. M. O vandalismo na escola e a dinâmica curricular. 1999. 209 f. Dissertação (Mestrado em Educação) - Universidade Católica de Brasília, Brasília, DF, 1999.

AQUINO, J. G. A indisciplina e a escola atual. Revista da Faculdade de Educação, São Paulo, v. 24, n. 2, p. 181-204, jul./dez. 1998a.

AQUINO, J. G. A violência escolar e a crise da autoridade docente. Cadernos Cedes, Campinas, v. 19, n. 47, p. 7-19, dez. 1998 b.

BOSACKI, S. L. The culture of classroom silence. New York: Peter Lang, 2005.

BOSSERT, S. T. Tasks and social relationships in classrooms: a study of instructional organization and its consequences. Cambridge: Cambridge University Press, 1979.

BOURDIEU, P.; PASSERON, J. C. La reproduction: éléments pour une théorie du système d'enseignement. Paris: Minuit, 1970.

CÂNDIDO, A. A estrutura da escola. PEREIRA, L.; FORACCHI, M. M. (Org.). Educação e sociedade. 6. ed. São Paulo: Nacional, 1973.

CANO, I.; SANTOS, N. Violência letal, renda e desigualdade no Brasil. 2. ed. Rio de Janeiro: 7 Letras, 2007.

CARREIRA, D. B. X. Violência nas escolas: qual o papel da gestão?. 2005. 183 f. Dissertação (Mestrado em Educação) - Universidade Católica de Brasília, Brasília, DF, 2005.

COLEMAN, J. S. The adolescent society: the social life of the teenager and its impact on education. New York: The Free Press of Glencoe, 1963.

CHRISPINO, A. Gestão do conflito escolar: da classificação dos conflitos aos modelos de mediação. Ensaio: avaliação e políticas públicas em educação, Rio de Janeiro, v. 15, n. 54, p. 11-28, jan./mar. 2007. 
CHRISPINO, A.; DUSI, M. L. H. M. Uma proposta de modelagem de política pública para a redução da violência escolar e promoção da cultura da paz. Ensaio: avaliação e políticas públicas em educação, Rio de Janeiro, v. 16, n. 61, p. 597624, out./dez. 2008.

DAYRELL, J. et al. Juventude e escola. In: SPOSITO, M. P. (Coord.). Estado da arte sobre juventude na pós-graduação brasileira: educação, ciências sociais e serviço social (1999-2006). Belo Horizonte: Argvmentvm, 2009. v. 1.

DEBARBIEUX, E. Violência escolar: um desafio mundial?. Lisboa, PT: Instituto Piaget, 2007.

DEBARBIEUX, E.; BLAYA, C. (Org.). Violência nas escolas e políticas públicas. Brasilia, DF: UNESCO, 2002.

DUBET, F. Le déclin de l'institution. Paris: Éditions du Seuil, 2002. . Le travail des sociétés. Paris: Éditions du Seuil, 2009.

FERNANDES, K. T. O conceito de violência escolar na perspectiva dos alunos. 2006. 154 f. Dissertação (Mestrado em Educação) - Universidade Católica de Brasilia, Brasilia, DF, 2006.

FREIRE, P. Pedagogia do oprimido. Rio: Paz e Terra, 1975.

GALVÃO, A. C. T. As escolas inovadoras: Distrito Federal. In: ABRAMOVAY, M. (Org.). Escolas inovadoras: experiências bem-sucedidas em escolas públicas. Brasilia, DF: UNESCO, 2003.

GOMES, C. A. (Org.). Abrindo espaços: múltiplos olhares. Brasilia, DF: UNESCO, Fundação Vale, 2008.

GOMES, C. A. et al. A violência na ótica de alunos adolescentes do Distrito Federal. Cadernos de Pesquisa, São Paulo, v. 36, n. 127, p. 11-34, jan./abr. 2006.

GONÇALVES, M. A. S. et al. Violência na escola, práticas educativas e formação do professor. Cadernos de Pesquisa, São Paulo, v. 35, n. 126, p. 635-658, set./dez. 2005.

GUIMARÃES, A. H. R. O orientador educacional frente ao fenômeno bullying: um estudo nas escolas particulares do Plano Piloto. 2008. 98 f. Dissertação (Mestrado em Educação) - Universidade Católica de Brasília, Brasília, DF, 2008. 
LIMA, D. A. Dores de ser adolescente. 2010. 166 f. Dissertação (Mestrado em Educação) - Universidade Católica de Brasília, DF, 2010.

LIRA, A. A organização escolar: relações entre clima e violências. 2010.

Dissertação (Mestrado em Educação) - Universidade Católica de Brasília, Brasilia, DF, 2010.

LOPES, R. B. Significações de violências na perspectiva de professores que trabalham em escolas "violentas". 171 f. Dissertação (Mestrado em Educação) Universidade Católica de Brasília, DF, 2004.

LOPES, R.; GALVÃO, A. C. T. Violência nas escolas: um fenômeno multifacetado. In: ENCONTRO DE PESOUISA EM EDUCAÇÃO DO CENTRO-OESTE, 7., 2004, Goiânia. Anais ... Goiânia: Ed. da UFG, 2004. v. 1.

MARQUES, L. R. Caminhos da democracia nas políticas de descentralização da gestão escolar. Ensaio: Avaliação e Políticas Públicas em Educação, Rio, v. 14, n. 53, p. 507-526, out./dez. 2006.

MARRIEL, L. C. et al. Violência escolar e auto-estima de adolescentes. Cadernos de Pesquisa, São Paulo, v. 36, n. 127, p. 35-50, jan./abr. 2006.

MINAYO, M. C. S. et al. Fala, galera: juventude, violência e cidadania. Rio: Garamond, 1999.

MOIGNARD, B. L'école et la rue: fabriques de délinquance. Paris: Presses Universitaires de France: Le Monde, 2008.

NIETZSCHE, F. W. Genealogia da moral. São Paulo: Cia das Letras, 2006.

NIZET, J.; HIERNAUX, P. Aborrecimento dos jovens na escola. Porto: Rés, [19-].

NJAINE, K.; MINAYO, M. C. S. Violência na escola: identificando pistas para a prevenção. Interface: Comunicação, Saúde, Educação, Botucatu, SP, v. 7, n. 13, p. 119-134, ago. 2003.

NOLETO, M. J. (Coord.). Abrindo espaços: educação e cultura para a paz = Making room: education and culture for peace. Brasilia, DF: UNESCO, 2001.

OLIVEIRA, M. G. P. Percepção de valores e violências nas escolas pelos docentes do ensino médio. 2003. 194 f. Dissertação (Mestrado) - Universidade Católica de Brasília, Brasília, DF, 2003. 
OLIVEIRA, M. G. P.; GOMES, C. A. Como docentes vêem valores e violências escolares no ensino médio. Revista Brasileira de Política e Administração da Educação, Rio de Janeiro, v. 20, n. 1, p. 45-70, jan./jun. 2004.

PENKAL, M. C. Representações sociais da violência: o crime e o castigo na perspectiva de adolescentes em situação de risco psicossocial. 2007. 133 f. Dissertação (Mestrado em Educação) - Universidade Católica de Brasilia, Brasília, DF, 2007.

PLACCO, V. M. N. S. et al. Representações sociais de jovens sobre violência e a urgência na formação de professores. Psicologia da Educação, São Paulo, n. 14/ 15, p. 15-29, 1/2. sem. 2002.

POMPEIA, R. O Ateneu. São Paulo: Câmara Brasileira do Livro, 1954. Disponível em: <http://www.dominiopublico.gov.br/download/texto/bn000005.pdf>. Acesso em: 5 abr. 2010.

RIBEIR0, M. Significações da violência escolar na perspectiva dos alunos. 2004. 135 f. Dissertação (Mestrado em Educação) - Universidade Católica de Brasília, Brasília, DF, 2004.

SANTANA, E. M. U. Policiais e educadores: papéis com fronteiras móveis? 2009. 186 f. Dissertação (Mestrado em Educação) - Universidade Católica de Brasília, Brasília, DF, 2009.

SANTOS, J. V. T. A violência na escola: conflitualidade social e ações civilizatórias. Educação e Pesquisa, São Paulo, v. 27, n. 1, p. 105-122, jan./jun. 2001.

SCHMITZ, T. A constituinte escolar no Rio Grande do Sul como política pública de um governo democrático popular: um estudo sobre o Instituto Estadual de Educação Prof. Pedro Schneider (S. Leopoldo/RS). 2007. 211 f. Dissertação (Mestrado) - Universidade do Vale do Rio dos Sinos, São Leopoldo, RS, 2007.

SILVA, J. M. A. P. S. Cultura escolar, autoridade, hierarquia e participação: alguns elementos para reflexão. Cadernos de Pesquisa, São Paulo, n. 112, p. 125-135, maio 2001.

SILVA, M. N. Escola e comunidade juntas contra a violência escolar: diagnóstico e esboço de plano de intervenção. 2004. 184 f. Dissertação (Mestrado em Educação) - Universidade Católica de Brasília, Brasilia, 2004.

SPOSITO, M. P. Um breve balanço da pesquisa sobre violência escolar no Brasil. Educação e Pesquisa, São Paulo, v. 27, n. 1, p.87-103, jan./jun. 2001. 
SPOSITO, M. P. A pesquisa sobre jovens na pós-graduação: um balanço da produção discente em Educação, Serviço Social e Ciências Sociais (1999-2006). In: . (Coord.). Estado da arte sobre juventude na pós-graduação brasileira: educação, ciências sociais e serviço social (1999-2006). Belo Horizonte: Argvmentvm, 2009. v. 1.

WAISELFISZ, J. J. (Coord.). Juventude, violência e cidadania: os jovens de Brasília. São Paulo: Cortez; Brasília, DF: UNESCO, 1998.

WALLER, W.W. The school and the community: 1932. GOODE, W. J.; FURSTENBERG JUNIOR, F. F.; MITCHELL, L. R. Willard W. Waller: on the family, education, and war. Chicago: The University of Chicago Press, 1970a.

The school as a social organism: 1932. GO0DE, W. J.; FURSTENBERG JUNIOR, F. F.; MITCHELL, L. R. Willard W. Waller: on the family, education, and war. Chicago: The University of Chicago Press, $1970 \mathrm{~b}$.

ZALUAR, A.; NORONHA, J. C.; ALBUQUERQUE, C. Violência: pobreza ou fraqueza institucional?. Cadernos de Saúde Pública, Rio de Janeiro, n. 10, p. 213-217, 1994. Suplemento 1.

Recebido em: 13/05/2010

Aceito para publicação em: 08/06/2010 